\title{
Traumatic dental injuries in a university hospital: a four-year retrospective study
}

\author{
Benjamin Mahmoodi ${ }^{1 *}$, Roman Rahimi-Nedjat ${ }^{2}$, Jens Weusmann ${ }^{1}$, Adriano Azaripour ${ }^{1}$, Christian Walter ${ }^{2}$ \\ and Brita Willershausen ${ }^{1}$
}

\begin{abstract}
Background: Traumatic dental injuries present complex injuries of the dentoalveolar system. Aim of this study was to investigate the frequency and patterns of traumatic dental injuries in a University dental emergency service over four years.

Methods: A retrospective investigation on all dental trauma patients presenting at the dental emergency service of the University Medical Center Mainz, Germany between 01/2010 and 12/2013 was conducted. Demographic data, the cause and type of trauma and the initial therapy were analyzed.

Results: Out of 16,301 patients, 1,305 patients (8\%; average age 14.7 years $\pm 15.7 ; 60.1 \%$ male, $39.9 \%$ female) came due to trauma. $63.9 \%$ of the traumas occurred on weekends. The most frequent reason for injuries was falls (54.6\%). No correlation could be found between the cause and the kind of trauma. In $48.6 \%$ of the cases only one tooth was involved, in $33.5 \%$ two. The permanent dentition was traumatized in $56.6 \%$ of cases, the deciduous teeth in $41.1 \%$. The most frequently affected tooth was the central upper incisor (61.0 \%). Hard-tissue injuries were significantly more frequent in the permanent dentition, while periodontal injuries were seen significantly more often in the deciduous dentition.

Conclusion: Eight percent of all patients seeking help at the dental emergency service presented with trauma, meaning that dental traumatology is one of the major topics in emergencies. To improve the quality of care, further public education, expert knowledge among dental professionals and a well-structured emergency service are necessary.
\end{abstract}

Keywords: Dental trauma, Dentoalveolar-trauma, Prevalence, Tooth injury

\section{Background}

Traumatic dental injuries (TDIs) often present as serious and complex injuries of the dentoalveolar system. Prevalences vary depending on cultural and social factors [13]. Mostly, TDIs occur at a young age, but they are observed in any age group [3, 4]. Factors associated with higher prevalences of dental injuries are increased overjet, class II type malocclusion, having orthodontic needs, and male gender $[5,6]$.

Studies show that dental trauma accounts for about $5 \%$ of all injuries leading to inpatient or outpatient treatment and that the oral region is the sixth most

\footnotetext{
* Correspondence: benjamin.mahmoodi@unimedizin-mainz.de

'Department of Operative Dentistry and Periodontology, University Medical Center of the Johannes Gutenberg-University Mainz, Augustusplatz 2, 55131 Mainz, Germany

Full list of author information is available at the end of the article
}

frequently injured part of the body [7, 8]. Mostly, TDIs involve anterior teeth and represent painful events that may result in complications such as crown discoloration, pulp necrosis, apical periodontitis, ankyloses, and inflammatory root resorption and tooth loss as a consequence of the above mentioned complications or primary event [9]. In addition to functional problems, traumatic dental injuries (TDIs) may cause aesthetic, psychological and social problems by affecting the appearance and speech of patients [10]. To minimize complications and to save the affected tooth, immediate and appropriate management is required.

The incidence of TDIs is higher in the late evenings and on weekends, which is associated with the lifestyle $[7,11]$. Consequently many patients present in dental emergency service units since they usually operate 
outside the dentists' regular clinical hours. Available data on the frequency and patterns of dental traumas in Germany are sparse but necessary to provide recommendations for prevention and improvement in the quality of the therapy.

As our institution is one of two university medical centers in the Rhine-Main-metropolitan region, which has 5.5 million inhabitants, our dental clinic is frequently sought out by dental emergency patients and in fact sees these patients daily. The aim of this retrospective study was to investigate the frequency of TDIs among all patients who presented to the dental emergency service within a period of four years.

\section{Methods}

All patients that presented in the dental emergency outpatient department of the University Medical Center of the Johannes Gutenberg-University in Mainz between January 2010 and December 2013 were included. Altogether, 16,301 patients were seen in the dental emergency outpatient department in the four-year period (average age 35.3 years $\pm 19.5,54.4 \%$ male [34.9 years \pm 19.1 ] and $45.6 \%$ female [35.8 years \pm 19.9$]$ ]). A retrospective investigation on these patients was then carried out concerning epidemiologic factors, the cause and the type of trauma as well as concomitant soft tissue injuries and the initial therapy. For this, electronic health records were reviewed and subjected to further analysis. Inpatient cases that had already had treatment in other departments, such as the departments for oral and maxillofacial surgery, trauma surgery, and neurosurgery, due to more severe injuries were excluded since these patients are usually transferred or presented at a later stage to the dental department and could thereby introduce a bias regarding the prognosis and sufficient treatment of the affected teeth.

Due to the hospital laws of each state in Germany (Landeskrankenhausgesetz), no ethical approval is necessary in retrospectively performed studies evaluating patient data that already exist. All patients were informed of the anonymized use of their records at the time they contacted the hospital for dental care.

\section{Classification of dental injuries}

Traumatic dental injuries were classified as follows [12]: (i) enamel crack, (ii) enamel fracture, (iii) enamel-dentin fracture without pulp exposition, (iv) enamel-dentin fracture with pulp exposition, (v) vertical crown-root fracture, (vi) root fracture, (vii) concussion, (viii) subluxation, (ix) lateral luxation, (x) intrusion and (xi) avulsion. (i)-(iv) were summarized as hard tissue injuries, (v) and (vi) as root fractures and (vii)-(xi) as periodontal injuries.

\section{Statistical analysis}

For statistical analysis, Microsoft Excel 2010 (Redmond, WA, USA) and SPSS 22 (IBM, Armonk, NY, USA) were used. The chi-square test was used for analysis of uneven distributions between two groups, such as the gender distribution and the distributions of the different kinds of traumas in relation to the dentition and/or the cause of trauma.

\section{Results}

Out of the 16,301 patients seen in the four-year period, $8.0 \%$ presented with TDIs $(n=1305$; average age 14.7 years $\pm 15.7,60.1 \%$ male [14.4 years \pm 13.8 ] and $39.9 \%$ female [ 15.2 years \pm 18.2$]$ ), with a male to female ratio of 1.5:1. Men were significantly more often affected than females $(p<0.001)$. The youngest patient presented at an age of 7 months, while the oldest patient was 88 years. More than half of the trauma collective $(54.6 \% ; n=713)$ was under the age of ten (Fig. 1).

Concerning the year and month of visit, a homogeneous distribution of trauma cases was found (Fig. 2). In 2010, 280 patients were treated, in 2011 354, in 2012 349 and in 2013322 patients. Nearly two-third (63.9 \%; $n=833$ ) of all TDIs occurred on weekends (Fig. 3). 74 patients $(5.7 \%)$ came on a public holiday. The most frequent reasons for TDIs (Table 1) were falls $(54.6 \%$; $n=$ 713), followed by sport accidents (13.4\%), and recreational accidents $(8.8 \%)$. Most of the sport accidents occurred in the patient group aged between 10 and 19 years (46.3\%), followed by the $0-10$ year-olds $(30.3 \%)$. Significant differences were seen in the frequency of the causes between the genders. While assaults were more often the trauma reason in male patients $(p<0.001)$, the frequency of falls was higher among females $(p<0.001)$. Most assaults occurred in the 20-29 year age group (48.3\%), followed by the $10-$ 19 year-olds (31\%).

Among the 1,305 patients, 2,319 teeth were traumatized (mean: 1.8 teeth per patient). In $48.6 \%(n=634)$ of the cases, only one tooth was involved; in $33.5 \%(n=$ 437) two teeth were injured, and in $16.7 \%(n=216)$ three or more teeth were injured. 337 patients $(25.8 \%)$ had a concomitant soft tissue injury. 18 patients (1.4\%) presented with a soft-tissue injury without dental involvement.

The permanent dentition was traumatized in $56.6 \%$ $(n=739)$ of cases, the deciduous teeth were traumatized in $41.1 \%(n=537)$, and eleven patients $(0.8 \%)$ had trauma to the transitional dentition with affection of the deciduous and permanent dentition (Fig. 4).

\section{Permanent dentition}

Among the 739 patients with permanent dentition, the average age was 23.0 years \pm 16.5 (63.1\% male [21.2 years 


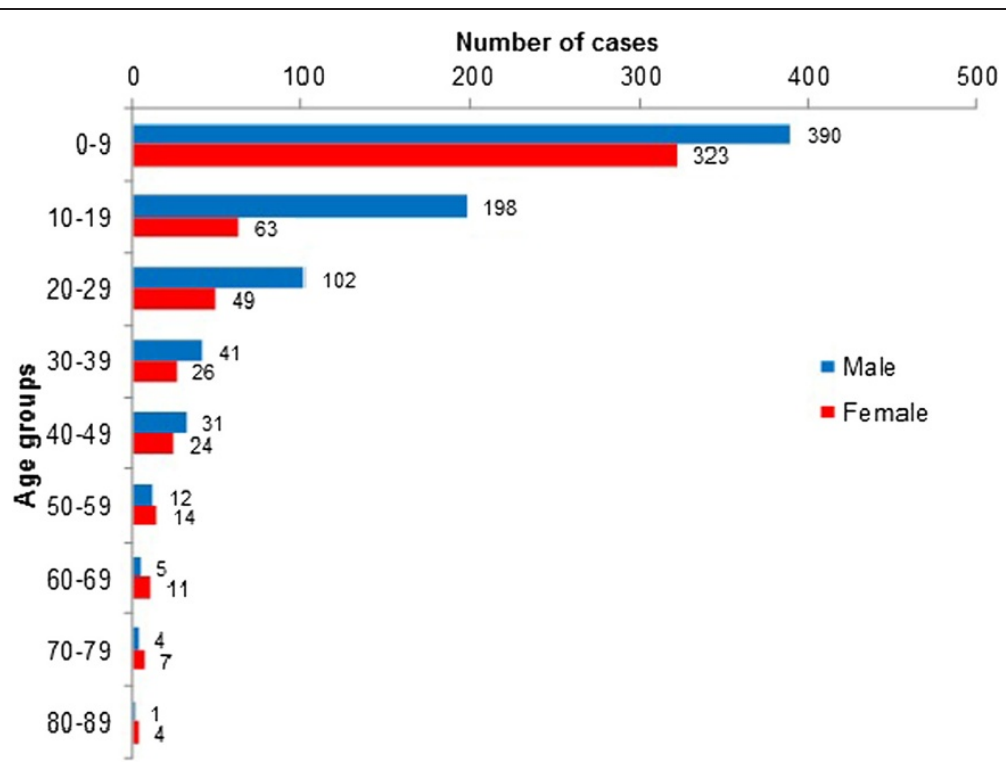

Fig. 1 Age and gender distribution of trauma patients

\pm 13.9 ] and $36.9 \%$ female [26.0 years \pm 19.7$]$ ), and the male to female ratio was $1.7: 1$. With a total of 1398 injured teeth, there was an average of 1.9 permanent dentition injuries per patient. $84.5 \%$ of the traumatized teeth were located in the upper jaw. The most frequently affected tooth was the central upper incisor $(61.0 \% n=$ 853, Fig. 4). Enamel dentin-fracture was the most frequently diagnosed condition (38.2\%), followed by subluxation (23.0 \%) and lateral luxation (17.9 \%, Fig. 5).

\section{Decidious dentition}

Among the 537 patients with deciduous dentition, the average age was 3.6 years \pm 2.0 (55.7\% male [3.7 years \pm 2.3 ] and $44.3 \%$ female [ 3.4 years \pm 1.7 ]), and the male to female ratio was 1.3:1. The mean number of injured teeth per patient was 1.7 (921 teeth in 537 patients). $88.2 \%$ of traumatized teeth were located in the upper jaw. Subluxation $(33.7 \%)$ was the most common diagnosis, followed by lateral luxation (27.6\%), avulsion (15.6\%) and intrusion (15.6 \%, Fig. 5).

\section{Type of trauma}

No correlation could be found between the cause of the trauma and the type of TDIs, but a comparison of the different dentitions showed significant differences in the type of trauma. While hard-tissue injuries appeared significantly more often in patients with permanent dentition $(p<0.001)$, periodontal injuries were found to be more frequent in the deciduous dentition $(p<0.001)$. There was no statistical difference in the distribution of

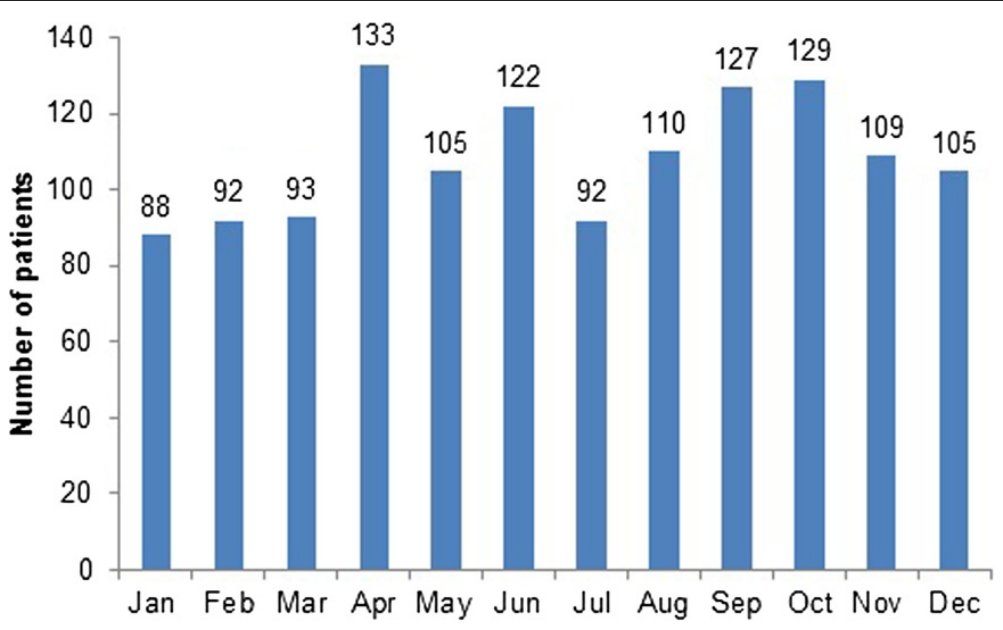

Fig. 2 Distribution of TDls among the months of the year 


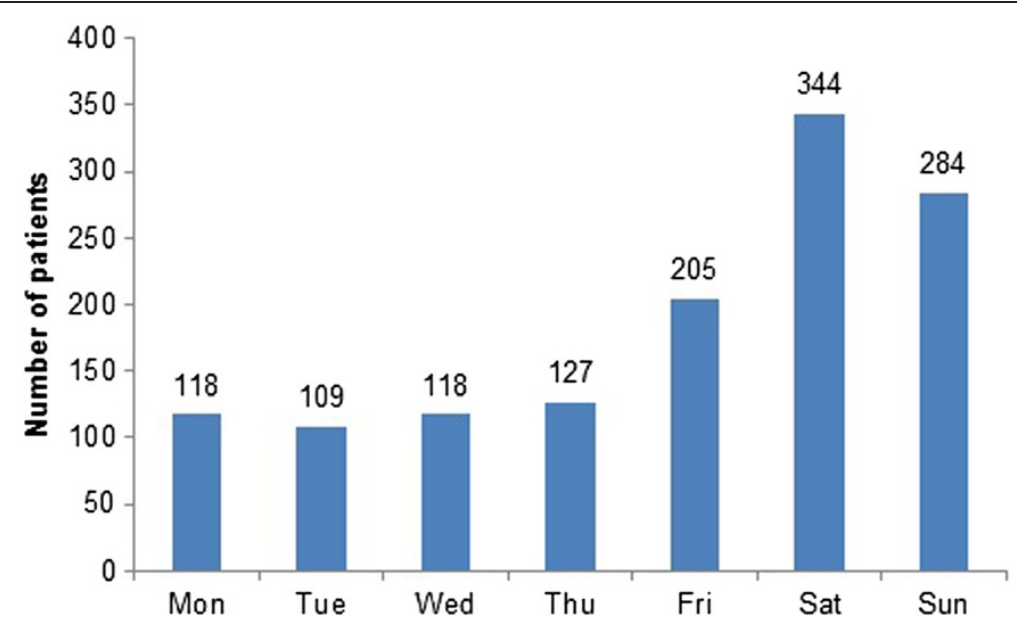

Fig. 3 Distribution of TDls among the days of the week

root fractures $(p=0.412) .10 .2 \%(n=133)$ of patients had a combination of hard tissue injury (diagnoses i-iv) and periodontal injury (diagnoses vii-xi), while the most common combination of diagnoses was subluxation and uncomplicated enamel-dentin-fracture $(4.1 \% ; n=54)$.

\section{Initial therapy}

In $60.2 \%$ of cases a dental, surgical and/or medical treatment was provided. The treatment measures are summarized in Table 2. As a matter of course, the remainder of the patients was seen by the dentist on duty, but no interventional therapy was indicated or possible.

\section{Discussion}

The prevalence of dental trauma in emergency patients ( $8 \%$ in the present study) distinctly varies depending on the countries where the studies were conducted. The prevalence is reported to be $66 \%$ in Korea [13], $27.7 \%$ in the United Kingdom [14], $11 \%$ in Greece [15], and $8.4 \%$ in France [16]. This range could be explained by the different health insurance systems; for example, in Germany basic dental treatment and emergency treatment are fully covered by health insurance. Patients in Korea must pay out-of-pocket for emergency treatment, so that only patients with severer problems might visit the clinic [13]. The range of prevalences might also be influenced by different socioeconomic and cultural diversities as well. Although the studies mentioned refer to TDIs in dental trauma, a deeper view on the various kinds, causes and localizations of TDIs was not given.

In contrast to other investigation, no seasonal increase of TDIs during warm months was found [13, 15]. The weekly distribution showed that the major prevalence of TDIs were on Saturdays, followed by Sundays and Fridays. This is associated with intense social activity, sports and leisure time as well as greater alcohol consumption on the weekends. These findings agree with former studies [11, 13, 17].

Men were more likely to visit the dental emergency service due to TDIs than women; men tend to be more prone to trauma than women $[4,9,11,18]$, perhaps because of more violent behavior and participation in more aggressive types of sports [19]. Our results show that the rate of sport accidents as well as assaults was higher

Table 1 Causes of trauma

\begin{tabular}{lccccc}
\hline Cause of trauma & Number of patients $n(\%)$ & Male $n(\%)$ & Female $n(\%)$ & Permanent dentition $n(\%)$ & Decidious dentition $n(\%)$ \\
\hline Total & $1305(100)$ & $784(100)$ & $521(100)$ & $739(100)$ & $537(100)$ \\
Falls (domestic) & $257(19.7)$ & $144(18.4)$ & $113(21.7)$ & $76(10.3)$ & $172(32.0)$ \\
Falls (outdoors) & $456(34.9)$ & $228(29.1)$ & $228(43.8)$ & $214(29.0)$ & $236(43.9)$ \\
Work accident & $22(1.7)$ & $17(2.2)$ & $5(1.0)$ & $22(3.0)$ & 0 \\
Sport accident & $175(13.4)$ & $128(16.3)$ & $47(9.0)$ & $146(19.8)$ & $81(11.0)$ \\
Assaults & $87(6.7)$ & $79(10.1)$ & $8(1.5)$ & $66(8.9)$ & $5(0.9)$ \\
Traffic accident & $81(6.2)$ & $56(7.1)$ & $25(4.8)$ & $65(8.8)$ & $12(2.2)$ \\
Recreation accident & $115(8.8)$ & $66(8.4)$ & $49(9.4)$ & $68(9.2)$ & $47(8.8)$ \\
Other & $112(8.6)$ & $66(8.4)$ & $46(8.8)$ & & $40(7.4)$ \\
\hline
\end{tabular}




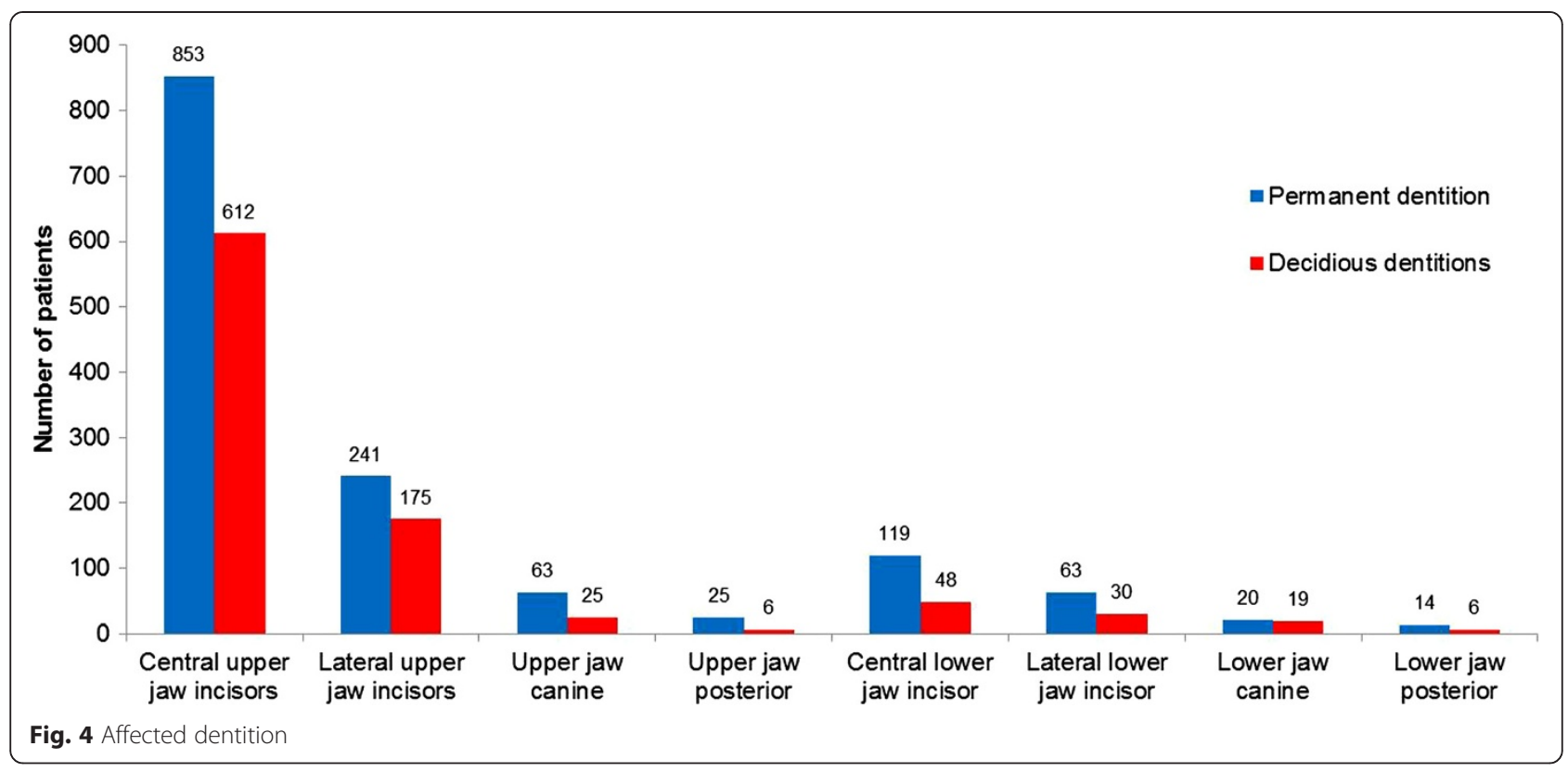

among the male collective. The difference in gender was less pronounced in patients with trauma in the deciduous dentition, which is consistent with the literature [20, 21].

An age peak was noticed in the 0-9 year-olds, with a continuous decrease with advancing age. Children are prone to TDIs because of their lack of motor coordination and curious and exploratory behavior [13], and the data presented here are in accordance with the literature $[3,4,9,13] .71-92 \%$ of all TDIs occur before the age of 19 years [3]. The proportion was $74.6 \%$ in this study.
The most common injury in the permanent dentition in our investigation was enamel-dentin-fractures without pulp involvement (38.4\%). This is consistent with the international literature, with a described range between $20.2 \%$ and $51.6 \%[4,9,18,22,23]$. In the deciduous dentition, subluxation was the injury most frequently seen $(33.7 \%)$. Other studies have shown a similar trend in the distribution of TDIs, with a higher number of soft-tissue injuries in the deciduous dentition and an increase in hard tissue injuries in the permanent dentition $[4,22-24]$. Because of the higher elasticity of the

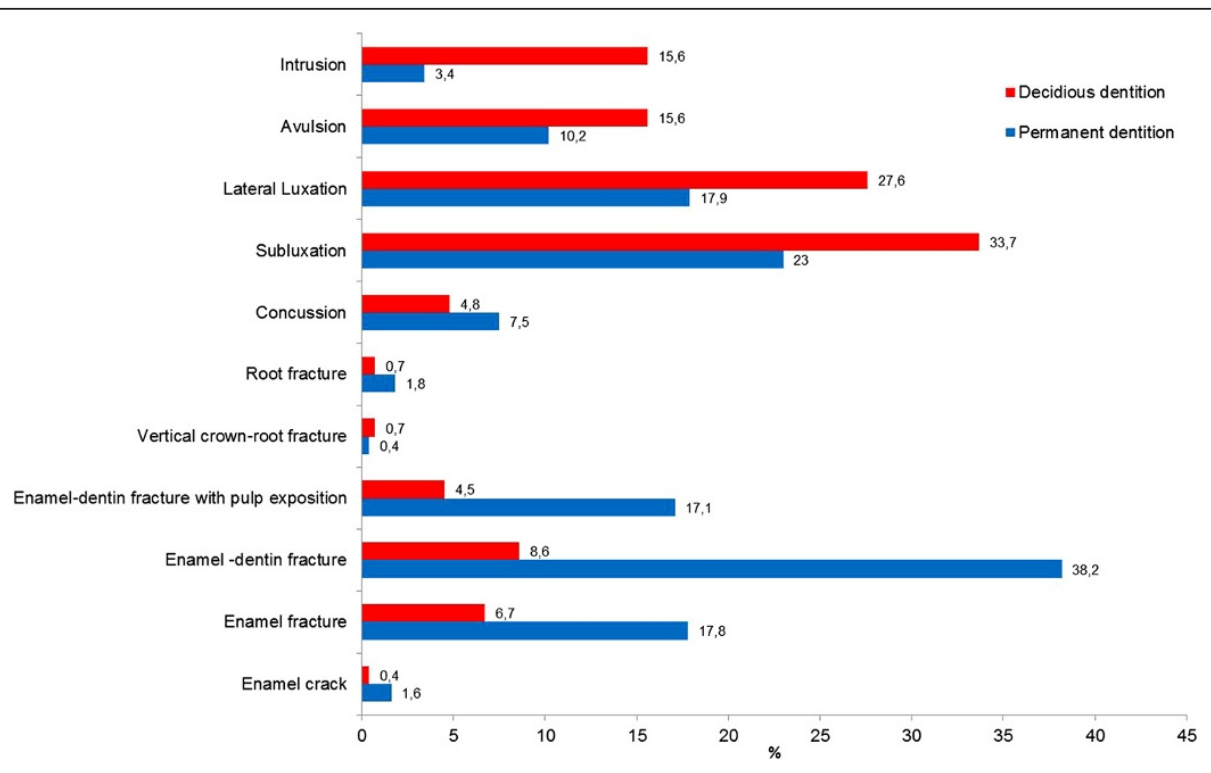

Fig. 5 Distribution of type of trauma 
Table 2 Provided treatment

\begin{tabular}{llll}
\hline & $\begin{array}{l}\text { Soft tissue } \\
\text { injury }\end{array}$ & $\begin{array}{l}\text { Hard tissue } \\
\text { injury }\end{array}$ & $\begin{array}{l}\text { Root } \\
\text { fractures }\end{array}$ \\
\hline Temporary filling & 52 & 287 & 4 \\
Trepanation & 12 & 44 & 4 \\
Suture & 88 & 70 & 1 \\
Splinting & 220 & 68 & 4 \\
$\begin{array}{l}\text { Extraction } \\
\text { Presciption of }\end{array}$ & 47 & 10 & 6 \\
$\begin{array}{l}\text { antibiotics } \\
\begin{array}{l}\text { Prescription of } \\
\text { analgetics }\end{array}\end{array}$ & 138 & 59 & 3 \\
\hline
\end{tabular}

supporting tissues, the relatively small roots and reduced alveolar bone support, the deciduous dentition has a predisposition for periodontal injuries, while permanent teeth are embedded more firmly in the alveolar bone and may be more likely to fracture [12]. In addition, the number of luxation injuries might be underestimated since minor luxation in patients with mixed dentition or periodontal disease are difficult to diagnose, and the patients might be less likely to consult a dentist.

Altogether, 1.8 teeth per trauma patient were injured, which is consistent with the range of 1.6 to 1.9 teeth per patient described in the literature $[4,11,18,22]$.

In agreement with the results of previous studies, the central and lateral upper jaw incisors were the teeth most frequently affected [3, 4, 18]. They account for $78.2 \%$ of all injured teeth in the permanent dentition and $85.5 \%$ in the deciduous dentition.

A high share of patients presenting to our emergency dental department did not receive any immediate interventional treatment. Some of these were patients with periodontal injuries in the deciduous dentition that were near exfoliation stage. In such patients, a conservative, "wait-and-watch" philosophy was applied rather than interventional treatment. Some patients presented with minimal hard tissue defects, such as enamel fractures with or without dentine involvement that did not include the pulp. In these patients, no emergency procedures were needed, but they were provided with an appointment at a mutually beneficial time. Certain pediatric patients also did not receive interventional emergency treatment; these were children with isolated dental avulsion injuries who either did not bring the tooth along with them or were cases where the avulsed tooth was a highly resorbed primary tooth that would have exfoliated in due course anyway.

Mostly TDIs happen in everyday life situations, which make them largely unavoidable. As a result, dental trauma is hard to prevent. Educational programs for teachers, parents, caregivers, coaches and paramedics could help to minimize the long term effects of trauma and to achieve better prognoses through immediate and correct treatment. Efforts to reduce environmental (e.g. unsafe school grounds and playgrounds) and behavioral risk-factors (e.g. alcohol consumption, school-bullying, high-risk sport activities, etc.) for TDIs may have an impact on prevention. Despite all efforts, they cannot be avoided in most situations. Sport injuries, which were the reason for trauma in $13.4 \%$ of cases, present opportunities for prevention. The use of mouth guards has been regarded as an effective measure to prevent or reduce the severity of dental trauma in sports [25]. From this perspective, it is important to sharpen about the awareness of the positive effects of these devices among coaches as well as the athletes themselves.

A limitation of the present study is the lack of followup. Based on our findings, future studies on clinical outcomes, complications and the long time survival rates could be conducted. However, our data give an overview of the prevalence of TDIs in a German metropolitan region.

The high proportion of weekend injuries that usually need immediate treatment to prevent long-term deficiencies shows the importance of dental emergency units so that patients receive the required care as soon as possible.

\section{Conclusion}

With an $8 \%$ share of all patients presenting to the emergency dental service and the impact on esthetics and function, we think TDIs can be regarded as a legitimate public health issue. To improve the quality of care, further public education, expert knowledge on the diagnosis and treatment of TDIs among dental professionals and a well-structured emergency service will be the key.

\section{Abbreviations \\ TDIs: Traumatic dental injuries.}

\section{Competing interests}

The authors declare that they have no competing interests.

\section{Authors' contributions}

BM carried out the study, was involved in the design and analysis and contributed to the write up the paper. RR was involved in the statistical analysis and the write up of the paper. CW participated in the design of the study and was involved in the statistical analysis. JW was involved in the design and contributed to the write up the paper. AA was involved in the design and statistical analysis. BW participated in the design and coordination of the study. All authors read and approved the final manuscript.

\section{Author details}

${ }^{1}$ Department of Operative Dentistry and Periodontology, University Medical Center of the Johannes Gutenberg-University Mainz, Augustusplatz 2, 55131 Mainz, Germany. ${ }^{2}$ Department of Oral and Maxillofacial and Facial Plastic Surgery, University Medical Center of the Johannes Gutenberg-University Mainz, Augustusplatz 2, 55131 Mainz, Germany.

Received: 17 June 2015 Accepted: 21 October 2015

Published online: 04 November 2015 


\section{References}

1. Rhouma O, McMahon AD, Conway DI, Armstrong M, Welbury R, Goodall C. Facial injuries in Scotland 2001-2009: epidemiological and sociodemographic determinants. Br J Oral Maxillofac Surg. 2013;51(3):211-6.

2. Glendor U. Aetiology and risk factors related to traumatic dental injuries-a review of the literature. Dent Traumatol. 2009;25(1):19-31.

3. Glendor U. Epidemiology of traumatic dental injuries-a 12 year review of the literature. Dent Traumatol. 2008;24(6):603-11.

4. Bucher K, Neumann C, Hickel R, Kuhnisch J. Traumatic dental injuries at a German university clinic 2004-2008. Dent Traumatol. 2013;29(2):127-33.

5. Borzabadi-Farahani A, Borzabadi-Farahani A. The association between orthodontic treatment need and maxillary incisor trauma, a retrospective clinical study. Oral Surg Oral Med Oral Pathol Oral Radiol Endod. 2011;112(6):e75-80.

6. Borzabadi-Farahani A, Borzabadi-Farahani A, Eslamipour F. An investigation into the association between facial profile and maxillary incisor trauma, a clinical non-radiographic study. Dent Traumatol. 2010;26(5):403-8.

7. Petersson EE, Andersson L, Sorensen S. Traumatic oral vs non-oral injuries. Swed Dent J. 1997;21(1-2):55-68.

8. Lin S, Levin L, Goldman S, Peleg K. Dento-alveolar and maxillofacial injuries: a 5-year multi-center study. Part 1: general vs facial and dental trauma. Dent Traumatol. 2008;24(1):53-5.

9. Hecova H, Tzigkounakis V, Merglova V, Netolicky J. A retrospective study of 889 injured permanent teeth. Dent Traumatol. 2010;26(6):466-75.

10. Rajab LD, Baqain ZH, Ghazaleh SB, Sonbol HN, Hamdan MA. Traumatic dental injuries among 12-year-old schoolchildren in Jordan: prevalence, risk factors and treatment need. Oral Health Prev Dent. 2013;11(2):105-12.

11. Santos SE, Marchiori EC, Soares AJ, Asprino L, de Souza Filho FJ, de Moraes $M$, et al. A 9-year retrospective study of dental trauma in Piracicaba and neighboring regions in the State of Sao Paulo, Brazil. J Oral Maxillofac Surg. 2010;68(8):1826-32.

12. Andreasen JO, Andreasen FM, Andersson L. Textbook and Color Atlas of Traumatic Injuries to the Teeth. Wiley; 2013

13. Bae JH, Kim YK, Choi YH. Clinical characteristics of dental emergencies and prevalence of dental trauma at a university hospital emergency center in Korea. Dent Traumatol. 2011;27(5):374-8.

14. Portman-Lewis S. An analysis of the out-of-hours demand and treatment provided by a general dental practice rota over a five-year period. Prim Dent Care. 2007;14(3):98-104.

15. Lygidakis NA, Marinou D, Katsaris N. Analysis of dental emergencies presenting to a community paediatric dentistry centre. International journal of paediatric dentistry / the British Paedodontic Society [and] the International Association of Dentistry for. Children. 1998;8(3):181-90

16. Tramini P. Al Qadi Nassar B, Valcarcel J, Gibert P. Factors associated with the use of emergency dental care facilities in a French public hospital. Spec Care Dentist. 2010;30(2):66-71.

17. Andersson L. Epidemiology of traumatic dental injuries. J Endod. 2013;39(3 Suppl):S2-5.

18. Caldas Jr AF, Burgos ME. A retrospective study of traumatic dental injuries in a Brazilian dental trauma clinic. Dent Traumatol. 2001;17(6):250-3.

19. Rahimi-Nedjat RK, Sagheb K, Walter C. Concomitant dental injuries in maxillofacial fractures - a retrospective analysis of 1219 patients. Dent Traumatol. 2014;30(6):435-41.

20. Hasan AA, Qudeimat MA, Andersson L. Prevalence of traumatic dental injuries in preschool children in Kuwait - a screening study. Dent Traumatol. 2010;26(4):346-50

21. Traebert J, Bittencourt DD, Peres KG, Peres MA, de Lacerda JT, Marcenes W. Aetiology and rates of treatment of traumatic dental injuries among 12year-old school children in a town in southern Brazil. Dent Traumatol. 2006;22(4):173-8.

22. Lam R, Abbott P, Lloyd C, Lloyd C, Kruger E, Tennant M. Dental trauma in an Australian rural centre. Dent Traumatol. 2008;24(6):663-70.

23. Sandalli N, Cildir S, Guler N. Clinical investigation of traumatic injuries in Yeditepe University, Turkey during the last 3 years. Dent Traumatol. 2005;21(4):188-94.

24. Wright G, Bell A, McGlashan G, Vincent C, Welbury RR. Dentoalveolar trauma in Glasgow: an audit of mechanism and injury. Dent Traumatol. 2007:23(4):226-31.

25. Maeda Y, Kumamoto D, Yagi K, Ikebe K. Effectiveness and fabrication of mouthguards. Dent Traumatol. 2009;25(6):556-64.

\section{Submit your next manuscript to BioMed Central and take full advantage of:}

- Convenient online submission

- Thorough peer review

- No space constraints or color figure charges

- Immediate publication on acceptance

- Inclusion in PubMed, CAS, Scopus and Google Scholar

- Research which is freely available for redistribution

Submit your manuscript at www.biomedcentral.com/submit 